\title{
Ocorrência de Aglae caerulea Lepeletier \& Serville (Hymenoptera, Apidae, Apini, Euglossina) no estado do Acre, Brasil
}

\section{Elder Ferreira Morato ${ }^{1}$}

\begin{abstract}
Occurrence of Aglae caerulea Lepeletier \& Serville (Hymenoptera, Apidae, Apini, Euglossina) in the State of Acre, Brazil. This note reports for the first time the presence of Aglae caerulea Lepeletier \& Serville, 1825 in the State of Acre, Western Amazonia. Three male bees were recorded in the "Parque Nacional da Serra do Divisor" with traps baited with methyl cinnamate. A general description of the sampling sites is provided.

KEY WORDS. Euglossina, Aglae caerulea, Acre, Amazonia, tropical forest
\end{abstract}

Aglae caerulea Lepeletier \& Serville, 1825 é a única espécie do gênero; é endêmica da região amazônica e Panamá, pouco representada nos museus e coleções zoológicas e muito pouco observada. Em virtude disso, pouco é conhecido sobre a sua biologia. Contudo, sabe-se que abelhas dessa espécie são cleptoparasitas, tendo sido criadas de ninhos de Eulaema nigrita Lepeletier, 1841 e Eufriesea spp. (ZUCCHI et al. 1969; DRESSLER 1982; KIMSEY 1987; BONILLA-GÓMEZ \& NATES-PARRA 1992).

O material tipo foi coletado em Caiena, Guiana Francesa. Um lectótipo fêmea encontra-se depositado no Instituto e Museo di Zoologia, Universita di Torino, Turim, Itália (KIMSEY \& DRESSLER 1986). Ocorre na Venezuela, oeste da Colômbia, Peru, norte da Bolívia, Guianas e Panamá (MOURE 1967; Dressler 1982; Bonilla-Gómez \& NATEs-PARRA 1992). Segundo Moure (1967) ela ocorre no Brasil nos estados do Amazonas, Pará e Amapá.

Embora vários inventários da fauna de Euglossina tenham sido realizados na Amazônia (Braga 1976; Pearson \& Dressler 1985; Powell \& Powell 1987; GONZÁlez \& GAIANI 1989; BECKER et al. 1991; MORATO et al. 1992; OLIVEIRA \& CAMPOS 1995), A. caerulea não foi coletada em nenhum deles. Mesmo no estudo de longo prazo (6-7 anos) realizado no Panamá por ROUBIK \& ACKERMAN (1987) essa espécie não foi coletada.

O último registro de coleta de $A$. caerulea publicado é o de Williams \& DoDson (1972). Esses autores coletaram três exemplares machos na localidade de Dawa, Guiana Inglesa, entre março e abril de 1970, em iscas contendo a substância odorífera metil cinamato. $\mathrm{O}$ local de coleta estava situado em uma região coberta por floresta tropical degradada.

Assim, o objetivo dessa comunicação é relatar a ocorrência dessa espécie no estado do Acre, Amazônia Ocidental, e descrever o ambiente em que foi coletada.

1) Departamento de Ciências da Natureza, Universidade Federal do Acre. 69915-900 Rio Branco, Acre, Brasil. 
Os exemplares foram registrados no Parque Nacional da Serra do Divisor (PNSD) durante a realização de uma avaliação ecológica rápida de sua biodiversidade com o objetivo de elaborar um plano de manejo.

O PNSD está situado a noroeste do estado do Acre, na fronteira com o Peru e possui superfície de 843.000 ha. O clima da região é quente e úmido, com temperatura média anual igual a $24,2^{\circ} \mathrm{C}$, máxima média anual igual a $37^{\circ} \mathrm{C}$ e mínima média anual igual a $5^{\circ} \mathrm{C}$. A pluviosidade varia entre 1.750 e $2.000 \mathrm{~mm}$ anuais. Os meses menos chuvosos são junho, julho e agosto. O relevo da maior parte do PNSD é colinoso com altitudes variando entre 200 e $580 \mathrm{~m}$, desenvolvido sobre argilitos de idade plio-pleistocênica e terciária. Na extremidade oeste ocorre uma zona de montanhas, o complexo fisiográfico da Serra do Divisor, o qual constitui um importante divisor de águas que formam as bacias dos rios Ucayali (oeste) e Juruá (leste). Os principais rios da região são o Moa e o Juruá. A maior parte da região possui vegetação do tipo floresta ombrófila aberta de palmeiras, de bambus e de cipós e floresta ombrófila densa sub-montana e de baixos platôs (BRASIL 1977).

Coletas de abelhas Euglossina foram realizadas em 12 sítios, os quais ficavam situados no interior de oito diferentes tipologias de vegetação. A amostragem foi dividida em duas etapas (novembro de 1996 e março de 1997). As abelhas foram coletadas por dois métodos [(1) captura direta usando rede entomológica e (2) armadilhas confeccionadas de garrafas plásticas de água mineral vazias], ambos usando iscas contendo substâncias odoríferas (cineol, benzil acetato, metil salicilato, eugenol, vanilina, benzil benzoato, metil cinamato, escatol e $\beta$-myrceno). Em cada sítio, no mesmo dia, um ponto foi escolhido para amostragem com rede entomológica e mais outros dois para amostragem com armadilhas. A amostragem foi realizada entre 7:00 e 16:00 horas, geralmente.

Ao todo, foram coletados 540 machos de Euglossina, entre os quais dois de $A$. caerulea. O primeiro exemplar foi coletado em um sítio localizado próximo ao Igarapé Anil (7²6'27' S e 7339'28" W), afluente do Rio Moa, região norte do PNSD, no interior de uma floresta ombrófila aberta de palmeiras, alta, rica em Orchidaceae e Bromeliaceae, sobre depósitos coluviais do Holoceno. O exemplar foi coletado em 09.XI.1996 em uma armadilha contendo a substância metil cinamato.

O segundo exemplar foi coletado em um sítio localizado próximo ao Igarapé Ramon ( $7^{\circ} 27^{\prime} 07^{\prime \prime S}$ e $\left.73^{\circ} 47^{\prime} 06^{\prime \prime} \mathrm{W}\right)$, também afluente do Rio Moa, região norte do PNSD, no interior de uma floresta ombrófila densa, baixa, sobre interflúvios colinosos do Plioceno. O exemplar foi coletado em 15.XI.1996 também em uma armadilha contendo a substância metil cinamato.

Embora não coletado, um terceiro espécime foi registrado em um sítio localizado próximo ao Rio Ouro Preto ( $8^{\circ} 24^{\prime} 19^{\prime \prime} \mathrm{S}$ e $\left.72^{\circ} 51^{\prime} 28^{\prime \prime} \mathrm{W}\right)$, afluente do Rio Juruá, localizado no interior de uma floresta ombrófila aberta de palmeiras. O espécime foi observado próximo a um cotonete de algodão embebido em metil cinamato às 9:10 horas da manhã em 16.III.1997.

A confirmação da identificação dos exemplares coletados foi realizada pelo Dr. Márcio Luiz de Oliveira (Universidade Federal do Acre) e Pe. Jesus Santiago Moure (Universidade Federal do Paraná). O material testemunha encontra-se depositado no Museu Regional de Entomologia da Universidade Federal de Viçosa e na coleção do autor. 
Embora várias armadilhas contendo metil cinamato tenham sido instaladas em outro sítios e tipologias de vegetação do PNSD, em nenhum foram coletados mais exemplares de A. caerulea. Os três exemplares coletados por Williams \& DoDSON (1972) em Dawa também foram atraídos por iscas contendo metil cinamato. Essa substância foi constatada nas flores de, pelo menos, 10 espécies de orquídeas e representa mais de $90 \%$ da substâncias odoriferas presentes nas fragrâncias de Aspasia epidendroides Lindl. e Stanhopea embreei Dodson (WILLIAMS \& WHITTEN 1983).

MOURE (1967) no mapa de distribuição dos gêneros de Euglossina (pág. 399), não incluiu a região da Serra do Divisor, Acre, na distribuição de $A$. caerulea.

Um programa mais extenso de coletas de abelhas Euglossina empregando iscas contendo metil cinamato nessa região do estado do Acre é, portanto, promissor para o estudo da ecologia das populações dessa espécie.

\begin{abstract}
AGRADECIMENTOS. À Dra. Verônica T. Passos (Instituto de Meio-Ambiente do Estado do Acre, Rio Branco, Acre, Brasil), coordenadora científica do "Projeto Para o Plano de Manejo do Parque Nacional da Serra do Divisor" pelo inestimável apoio no planejamento e execução do programa de amostragem e avaliação da biota do PNSD. À Fundação S.O.S. Amazônia, Rio Branco, Acre, Brasil, pela oportunidade e apoio financeiro dos trabalhos de campo.
\end{abstract}

\title{
REFERÊNCIAS BIBLIOGRÁFICAS
}

Becker, P.; J.S. Moure \& F.J.A. Peralta. 1991. More about euglossine bees in Amazonian forest fragments. Biotropica 23 (4b): 586-591.

Bonilla-Gómez, M.A. \& G. Nates-Parra. 1992. Abejas euglosinas de Colombia (Hymenoptera: Apidae). I. Claves ilustradas. Caldasia 17: 149-172.

BRAGA, P.I.S. 1976. Atração de abelhas polinizadoras de Orchidaceae com auxílio de iscas-odores na campina, campinarana e floresta tropical úmida da região de Manaus. Ciência Cultura 28 (7): $767-773$

BRASIL. 1977. Projeto RadambrasiL: levantamento de recursos naturais. Rio de Janeiro, Vol. 13, folhas SB/SC, 18, Javari/Contamana.

Dressler, R.L. 1982. Biology of the orchid bees (Euglossini). Ann. Rev. Ecol. Syst. 13: 373-394.

GonZALEZ, J.M. \& M.A. GAiAni. 1989. Lista preliminar de los Euglossini (Hymenoptera: Apidae) del Marahuaka, Parque Nacional Duida, T.F.A., Venezuela. Acta Terramaris 1: 81-83.

KIMSEY, L.S. 1987. Generic relationships within the Euglossini (Hymenoptera: Apidae). Syst. Entomol. 12: 63-72.

Kimsey, L.S. \& R.L. Dressler. 1986. Synonymic species list of Euglossini. Pan-Pac. Entomol. 62 (3): 229-236.

Morato, E.F.; L.A. DE O. CAmpos \& J.S. Moure. 1992. Abelhas Euglossini (Hymenoptera, Apidae) coletadas na Amazônia Central. Revta bras. Ent. 36 (4): 767-771.

Moure, J.S. 1967. A check-list of the known euglossine bees (Hymenoptera, A pidae). Atas Simp. Sobre Biota Amazônica, Zoologia, 5: 395-415.

OLIVEIRA, M.L. \& L.A. DE O. CAmpos. 1995. Abundância, riqueza e diversidade de abelhas Euglossinae (Hymenoptera, Apidae) em florestas continuas de terra firme na Amazônia Central, Brasil. Revta bras. Zool. 12 (3): 547-556.

Pearson, D.L. \& R.L. Dressler. 1985. Two-year study of male orchid bee (Hymenoptera: Apidae: Euglossini) attraction to chemical baits in lowland south-eastern Peru. Jour. Trop. Ecol. 1: 37-54. 
PowelL, A.H. \& G.V.N. PowelL. 1987. Population dynamics of male euglossine bees in Amazonian forest fragments. Biotropica 19 (2): 176-179.

ROUBIK, D.W. \& J.D. ACKERMAN. 1987. Long-term ecology of euglossine orchid-bees (Apidae: Euglossini) in Panama. Oecologia 73: 321-333.

Williams, N.H. \& C.H. Dodson. 1972. Selective attraction of male euglossine bees to orchid floral fragrances and its importance in long distance pollen flow. Evolution 26: 84-95.

WiLLiams, N.H. \& W.M. WhitTEN. 1983. Orchid floral fragrances and male euglossine bees: methods and advances in the last sesquidecade. Biol. Bull. 164: 355-395.

ZucChI, R.; S.F. SAKagami \& J.M.F. CAMARgo. 1969. Biological observations on a neotropical parasocial bee Eulaema nigrita, with a review of the biology of Euglossinae. A comparative study. Jour. Fac. Sci. Hokkaido Univ., Ser. VI Zool., 17: 271-380.

Recebido em 28.IX.2000; aceito em 18.VII.2001. 